\title{
Níveis de nitrogênio e a taxa fotossintética do mamoeiro "golden"
}

\author{
Nitrogen levels and photosynthetic rate of papaya 'golden'
}

\section{Jailson Lopes Cruz ${ }^{\mathrm{I}}$ Claudinéia Regina Pelacani ${ }^{\mathrm{II}}$ José Eduardo Borges de Carvalho ${ }^{\mathrm{I}}$ Luiz Francisco da Silva Souza Filho ${ }^{\text {III }}$ Dyane Coelho Queiroz ${ }^{\text {III }}$}

\section{RESUMO}

Objetivou-se neste trabalho, avaliar o efeito da nutrição nitrogenada sobre alguns aspectos relacionados à taxa fotossintética em plantas de mamão da variedade "Golden". As plantas foram cultivadas em vasos sob condições de casa de vegetação, em soluções nutritivas contendo três concentrações de $\mathrm{N}_{-\mathrm{NO}_{3}^{-}}^{-}\left(1,0 ; 5,0\right.$ e 8,0 molm $\left.{ }^{-3}\right)$. O delineamento experimental foi em blocos casualizados, com sete repetições. As avaliações foram realizadas 61 dias após o início do experimento. Observou-se que a deficiência de nitrogênio reduziu a matéria seca total; no entanto, a relação raiz:parte aérea foi maior nessas plantas. A taxa fotossintética líquida foi reduzida pela menor disponibilidade de nitrogênio. Os resultados observados para a condutância estomática e a correlação negativa encontrada entre a taxa fotossintética e a concentração interna de $\mathrm{CO}_{2}$ claramente indicam que a menor taxa fotossintética não foi devida à limitação estomática. Adicionalmente, a redução verificada nas concentrações de pigmentos foliares, como as clorofilas a e b e os carotenóides, também pode ter contribuído para a menor taxa fotossintética e o menor crescimento das plantas. A taxa transpiratória foi maior para as plantas cultivadas sob estresse; como conseqüência, observou-se, para essas plantas, menor ganho de $\mathrm{CO}_{2}$ por unidade de água transpirada.

Palavras-chave: taxa fotossintética, condutância estomática, matéria seca, eficiência no uso de água, clorofila, carotenóides.

\section{ABSTRACT}

This research was aimed at evaluating the effect of nitrogen $(N)$ levels on some aspects related to the photosynthetic rate in plants of papaya $\mathrm{Cv}$. Golden. The plants were cultivated under greenhouse conditions on different nutritional solutions with three concentrations of $\mathrm{N}_{-} \mathrm{NO}_{3}^{-}\left(1.0 ; 5.0 ; 8.0 \mathrm{molm}^{-3}\right)$.
The experiment was carried out under a randomized blocks experimental design, with seven repetitions. The evaluations occurred on the 61st day after the beginning of the experiment. The nitrogen deficiency reduced the total dry mass; however, the relation root:shoot was highest for these plants. The photosynthetic rate was reduced by the lesser nitrogen availability. The results observed for the stomatal conductance and the negative correlation found between the photosynthesis and the internal concentration of $\mathrm{CO}_{2}$, indicate clearly that the reduced photosynthetic rate was not due to stomatal limitation. Additionally, the reduction verified in leaf pigments, such as chlorophylls $a$ and $b$ and carotenoids also could have been contributed for the reduction on photosynthesis rate and growth of these plants. Transpiratory rate was higher for the plants cultivated under stress; as consequence it was observed, for these plants, minor $\mathrm{CO}_{2}$ profit for unit of transpirated water.

Key words: photosynthesis; stomatal conductance; dry mass, water use efficiency, chlorophyll, carotenoids.

\section{INTRODUÇÃo}

O mamoeiro é uma planta tropical que encontrou excelentes condições de cultivo comercial nas diversas regiões do Brasil, maior produtor mundial da fruta, com um volume de 1,7 milhões de toneladas de frutos. Em 2004, a produtividade média do mamoeiro foi de 44,7tha ${ }^{-1}$ (IBGE, 2005), um valor bastante inferior ao potencial produtivo dessa cultura, que é superior a 90tha ${ }^{-1}$, obtido em condições de campo (OLIVEIRA \& CALDA, 2004). Um dos motivos dessa enorme diferença está relacionado, entre outros fatores, ao

IEmbrapa Mandioca e Fruticultura Tropical, CP 007, 44 380-000, Cruz das Almas, BA, Brasil. E-mail: jailson@cnpmf.embrapa.br. Autor para correspondência.

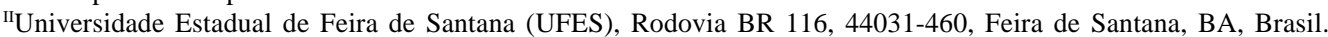

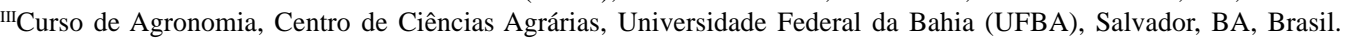


manejo inadequado da adubação nitrogenada, visto que a aplicação do nitrogênio, na quantidade e no tempo certos, é importante para a obtenção de altas produtividades (OLIVEIRA \& CALDA, 2004).

O nitrogênio tem sido considerado um dos principais nutrientes a limitar o crescimento e a produtividade dos vegetais. Assim é que plantas cultivadas com quantidades inadequadas de nitrogênio normalmente não expressam o seu potencial produtivo, visto que, sob tais condições, podem ocorrer reduções significativas na taxa assimilatória líquida de $\mathrm{CO}_{2}$ (EVANS, 1989), um dos principais determinantes do crescimento vegetal. O efeito negativo da deficiência de nitrogênio sobre a taxa fotossintética pode estar relacionado, dentre outros fatores, à redução no conteúdo de clorofila (CIOMPI et al., 1996), à redução na quantidade de tecido paliçádico (KOZLOWSKI \& PALLARDY, 1997), à redução da atividade de algumas enzimas do ciclo redutivo do carbono (SUGIHARTO et al., 1990) e do nitrogênio (DELÚ-FILHO, 1994) e à redução na condutância estomática ao vapor d’água (GUIDI et al., 1998).

O aumento na disponibilidade de nitrogênio normalmente traz como conseqüência efeitos positivos sobre a taxa de assimilação de carbono, já que esse nutriente faz parte dos principais componentes do sistema fotossintético, tais como clorofilas, carboxilase/ oxigenase da ribulose 1,5 bisfosfato (RubisCO) e carboxilase do fosfoenolpiruvato (PEPcase) (CORREIA et al., 2005). Quase sempre existe uma forte associação entre a taxa fotossintética e a concentração de nitrogênio foliar, independentemente se a relação for expressa com base na área ou na matéria seca (EVANS, 1989). Além do efeito sobre a assimilação de carbono, o nitrogênio também pode modular o particionamento de matéria seca entre a raiz e a parte aérea. Diversos autores têm evidenciado que a menor disponibilidade de nitrogênio tende a aumentar o particionamento em direção ao sistema radicular, determinando uma relação raiz:parte aérea maior (RUFTY Jr. et al., 1984; EGHBALL \& MARANVILLE, 1993).

Apesar de ser comum a ocorrência de plantios de mamão em solos com algum grau de deficiência de nitrogênio, os trabalhos visando a avaliar as conseqüências disso sobre a fisiologia dessa cultura ainda são bastante escassos. O objetivo do presente trabalho foi o de avaliar o efeito do nitrogênio sobre a taxa fotossintética do mamoeiro. Esses estudos são importantes, na medida em que podem servir como subsídios aos trabalhos de melhoramento e nutrição de plantas que visem a identificar e ou criar genótipos mais eficientes no uso desse nutriente.

\section{MATERIAL E MÉTODOS}

O presente trabalho foi desenvolvido em casa de vegetação, na Embrapa Mandioca e Fruticultura Tropical, localizada em Cruz das Almas/Bahia, utilizando-se a variedade "Golden". Essa variedade apresenta bom potencial produtivo e atualmente é bastante utilizada em plantios comerciais. As sementes foram selecionadas, classificadas e colocadas para germinar em vasos plásticos pretos com capacidade para 2,2dm ${ }^{3}$.

O substrato utilizado para o plantio foi composto de uma mistura de vermiculita expandida e turfa processada, o qual foi lavado várias vezes com água de torneira, visando à retirada de todos os nutrientes que se encontrassem disponíveis. Inicialmente foram plantadas cinco sementes em cada vaso. Nos primeiros quinze dias, as plântulas foram irrigadas duas vezes ao dia, apenas com água de torneira. Após esse período, foram descartadas as menos vigorosas e o experimento passou a ser conduzido com uma plântula por vaso. Essas plântulas passaram, então, a ser fertilizadas com soluções nutritivas preparadas para apresentar três concentrações de $\mathrm{N}^{-\mathrm{NO}_{3}}{ }^{-}\left(1,0 ; 5,0\right.$; e $\left.8,0 \mathrm{molm}^{-3}\right)$. Os demais nutrientes foram iguais aqueles utilizados por CRUZ et al. (2004). A renovação das soluções ocorria a cada 15 dias, com $\mathrm{pH}$ corrigido para um valor entre 6,5 e 6,7. Diariamente era realizada a reposição da água evapotranspirada. O delineamento experimental foi em blocos casualisados e com sete repetições, sendo cada planta considerada uma parcela experimental. Após 61 dias de cultivo, o experimento foi encerrado.

No horário entre as 09h e 10h, e na última folha totalmente expandida, mediu-se as trocas gasosas com um analisador de gás no infravermelho (IRGA), portátil, modelo LCA-4, em sistema aberto, com câmara foliar do tipo Parkinson (Analytical Development Company, Hoddesdon, UK) e fluxo de ar de $250 \mathrm{~mL} \mathrm{~min}^{-1}$. Para evitar-se que as variações climáticas ocorridas ao longo do horário de avaliação afetassem a tomada de dados, as avaliações foram realizadas por blocos. Dos mesmos lóbulos utilizados para a avaliação das trocas gasosas, foram retirados dois discos foliares (totalizando $1,327 \mathrm{~cm}^{2}$ ) e utilizados para a determinação das clorofilas e dos carotenóides. Os discos foram imersos em 10,0mL de dimetil sulfóxido (DMSO) e colocados no escuro por quatro dias, à temperatura ambiente. Em seguida, e ainda no escuro, as absorbâncias dos extratos foram lidas a 470, 646 e 663nm, utilizando-se como branco o DMSO. As concentrações de carotenóides e clorofilas $a$ e $b$ foram determinadas com base nas equações definidas por WELLBURN (1994). 
Posteriormente, as folhas, o caule, o pecíolo e as raízes foram destacados das plantas e colocados para secar a $70^{\circ} \mathrm{C}$ em estufa com circulação forçada de ar, até atingirem estabilização da matéria seca. Após terem sido secados e moídos, foram tomados $100 \mathrm{mg}$ do material foliar para a análise de nitrogênio total no Laboratório de Solos e Nutrição de Plantas da Embrapa Mandioca e Fruticultura Tropical.

Para efeito de comparação entre os tratamentos, calculou-se, para cada média, seu respectivo erro padrão (EPM). A sobreposição das barras do EPM indica a falta de diferenças estatísticas entre os tratamentos.

\section{RESULTADOS E DISCUSSÃO}

A concentração de nitrogênio nas folhas das plantas cultivadas com $1,0 \mathrm{molm}^{-3}$ de $\mathrm{N}^{-N_{3}}{ }_{3}^{-}$foi de $27,7 \mathrm{~g}\left(\mathrm{~kg} \mathrm{MS}^{-1}\right)$, enquanto, para as plantas cultivadas com $8,0 \mathrm{molm}^{-3}$, a concentração de nitrogênio foi de $38,0 \mathrm{~g}\left(\mathrm{~kg} \mathrm{MS}^{-1}\right)$ (Figura 1A). Valores semelhantes foram encontrados por CRUZ et al. (2004) em trabalho com a variedade de mamoeiro "Sunrise solo", também em casa de vegetação. O menor valor de matéria seca total (MST) foi obtido para as plantas cultivadas no substrato irrigado com 1,0 molm ${ }^{-3}$ de $\mathrm{N}_{-} \mathrm{NO}_{3}^{-}$(Figura $1 \mathrm{~B}$ ). Aqui, ao contrário do observado para os valores de nitrogênio foliar, houve diferença estatística entre as concentrações de 5,0 e $8,0 \mathrm{molm}^{-3}$ para essa característica. Em consonância com o que foi observado por CRUZ et al. (2004), os menores acúmulos de matéria seca das plantas cultivadas sob menor suprimento de nitrogênio foi conseqüência da redução de todos os componentes de crescimento avaliados (matérias secas do caule, pecíolos, folhas e raízes e número e tamanho médio da folhas; dados não apresentados).

Os níveis de nitrogênio do presente trabalho foram escolhidos para que as plantas pudessem crescer com um intervalo de deficiência a excesso de suprimento desse nutriente (CRUZ et al., 2004). Esses autores encontraram que a variedade "Sunrise solo" estabilizava seu crescimento com a aplicação de 3,0 molm ${ }^{-3}$ de $\mathrm{N}_{-} \mathrm{NO}_{3}^{-}$. No entanto, o que se verificou foi que a variedade “Golden” continuou a acumular matéria seca mesmo com aplicações superiores a $5,0 \mathrm{molm}^{-3}$. Nesse sentido, estudos estão sendo conduzidos para verificar se essas diferenças de resultados são devidas a variabilidades genéticas na eficiência quanto ao uso de nitrogênio ou meramente refletem a influência de fatores ambientais, devido à variação entre as épocas em que foram conduzidos os respectivos experimentos. Para a relação raiz:parte aérea, verificou-se que os maiores valores foram obtidos pelas plantas cultivadas com baixos suprimentos de nitrogênio, o que evidencia ajuste na partição de assimilados entre os órgãos da planta do mamoeiro “Golden” (Figura 1C).

Os valores de área foliar obtidos foram de 2,74; 9,87 e 16,39 $\mathrm{dm}^{2}$, respectivamente, para as plantas dos tratamentos 1,0; 5,0 e 8,0 molm $^{-3}$ de N-NO ${ }_{3}^{-}$(Figura 1D). A redução proporcionada pelo menor nível de nitrogênio foi de 84\%. Diminuição na área foliar tem sido considerada um dos efeitos mais significativos da deficiência de nitrogênio (VOS \& Van Der PUTTEN, 1998), o que pode estar relacionado à redução na emissão de novas folhas e ao menor crescimento das folhas formadas, em função da redução do potencial de pressão celular (RADIN \& BOYER, 1982), ao aumento provocado na rigidez da parede celular (PALMER et al., 1996) e/ou à redução da divisão celular (JOVANOVIC et al., 2004). Vale ressaltar que a manutenção da área foliar, induzida pelo suprimento adequado de nitrogênio, também é importante para promover maior interceptação da energia solar incidente e, por conseguinte, determinar maior assimilação de carbono, o qual pode contribuir, significativamente, para aumentar o acúmulo de matéria seca pelas plantas.

Além de promover alterações na alocação do carbono assimilado, como visto pela relação raiz:parte aérea, verificou-se que a deficiência de nitrogênio regulou negativamente a própria taxa de assimilação do carbono (Figura 1E), e esse pode ter sido um dos fatores responsáveis pelo decréscimo no acúmulo de matéria seca total dessas plantas. A redução da taxa fotossintética induzida pela deficiência severa $\left(1,0 \mathrm{molm}^{-3}\right)$ em relação ao nível de $8,0 \mathrm{molm}^{-3}$ foi de $18,2 \%$. Influência negativa do nitrogênio sobre a taxa fotossintética tem sido observada para diversas espécies e é explicada pelo fato de que a aplicação desse nutriente determina a formação de compostos relacionados à fotossíntese tais como transportadores de elétrons e RubisCO (EVANS, 1989). Adicionalmente, concentrações ótimas de nitrogênio podem ser necessárias para a manutenção da atividade carbixilativa da RubisCO (CRUZ et al., 2001). Plantas de mamão cultivadas sob deficiência de nitrogênio têm um expressivo aumento na concentração de amido nos cloroplastos (CRUZ et al., 2004), e esse acúmulo normalmente é acompanhado por danos aos tilacóides (BONDADA \& SYVERTSEN, 2005), o que também ajuda a explicar a redução da taxa fotossintética nessas condições.

A essencialidade do nitrogênio para a obtenção de elevadas taxas fotossintéticas no mamoeiro é evidenciada pela relação positiva e significativa entre essas duas características (Figura 1F). Apesar de significativo, o baixo valor observado

Ciência Rural, v.37, n.1, jan-fev, 2007. 

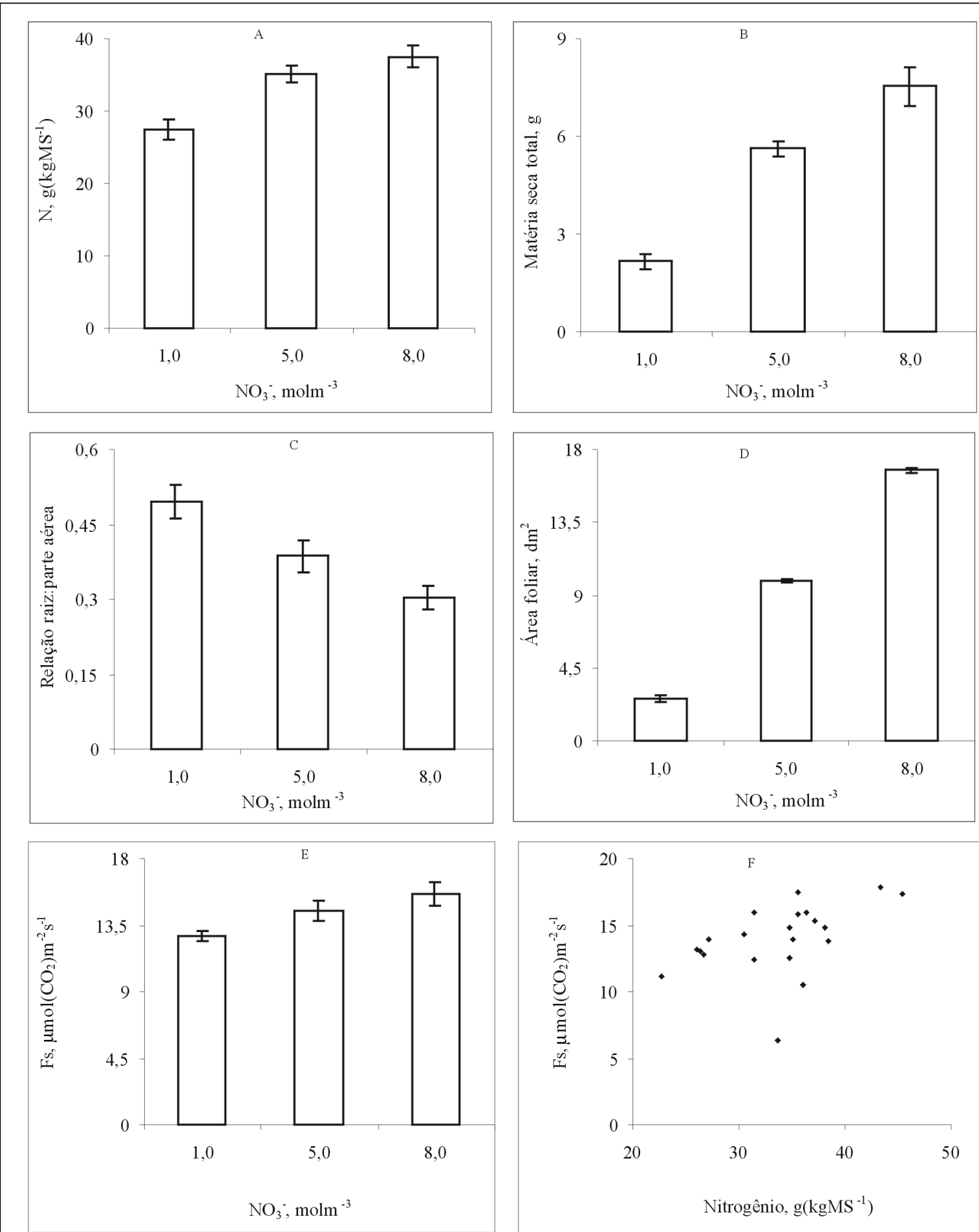

Figura 1 - Efeito de níveis de nitrogênio sobre a concentração de nitrogênio foliar (A), matéria seca total (B), relação raiz: parte aérea (C), área foliar (D), taxa fotossintética (E) e correlação entre a concentração de nitrogênio foliar e a fotossíntese (F) do mamoeiro “Golden”, cultivado por 61 dias em solução nutritiva. Barras representam o erro padrão da média (n=7). 
para o coeficiente de correlação entre nitrogênio e taxa fotossintética pode ser atribuído à utilização da concentração média de nitrogênio de todas as folhas, ao contrário de outros autores que têm utilizado uma única folha para as determinações da taxa fotossintética e da concentração de nitrogênio, visando a estimar os valores da correlação.

Nas plantas cultivadas com $1,0 \mathrm{molm}^{-3}$ de nitrogênio, a redução da taxa fotossintética foi acompanhada pela manutenção da condutância estomática (Figura 2A); portanto, a redução da taxa fotossintética não foi devida à limitação ao ingresso de $\mathrm{CO}_{2}$, fato esse corroborado pela associação negativa entre essa característica e a concentração interna de $\mathrm{CO}_{2}$ (Figura 2B). Assim, pode-se sugerir que a redução da taxa fotossintética deve-se, entre outros fatores, ao efeito negativo do nitrogênio sobre a condutância do mesófilo e não por promover alterações nas características dos estômatos. Altas concentrações de amido no cloroplasto de plantas cultivadas sob deficiência de nitrogênio, como anteriormente mencionado, podem contribuir para a redução da condutância do mesofilo e dificultar o ingresso do $\mathrm{CO}_{2}$ nos sítios de carboxilação, à semelhança do que foi observado por GUIDI et al. (1998).

Verificou-se que a taxa transpiratória foi maior para as plantas cultivadas com 1,0 e 5,0 molm $^{-3}$ de

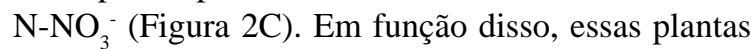
apresentaram menores eficiências no uso de água (Figura 2D), ou seja, menor ganho de carbono por quantidade de água transpirada. Esses resultados indicam que plantas de mamão “Golden”, quando cultivadas sob deficiência de nitrogênio, não apresentam ajuste estomático para minimizar a perda de água.

A menor disponibilidade de nitrogênio reduziu as concentrações das clorofilas $a$ e $b$ (Figuras $2 \mathrm{E}$ e $2 \mathrm{~F}$ ), podendo este ser outro fator a ter contribuído para a menor taxa fotossintética e o menor crescimento dessas plantas, em função da importância desses pigmentos para a absorção dos fótons e para o transporte de elétrons (HELDT, 1997). No entanto, a relação entre a clorofila $a$ e $b$ foi maior para as plantas cultivadas sob deficiência (Figura 3A), indicando maiores quantidades de centros de reação (PSII) e menor capacidade para a captura da energia solar incidente, por intermédio do complexo coletor (LCHII) (TERASHIMA \& EVANS, 1988; TERASHIMA \& HIKOSAKA, 1995). Essa estratégia pode servir para ajustar a capacidade na captura de energia com a redução da capacidade de utilização dessa energia pelas plantas. A deficiência de nitrogênio também reduziu a concentração dos carotenóides em, aproximadamente,
13,4\% (Figura 3B). Considerando-se que esses compostos são importantes para a proteção dos fotossistemas (TAIZ \& ZEIGER, 1998), pode-se sugerir que plantas cultivadas sob deficiência de nitrogênio também podem apresentar-se mais susceptíveis aos efeitos negativos de alguns estresses que possam induzir danos ao seu sistema fotossintético, como, o estresse hídrico e a salinidade.

A imposição do estresse de nitrogênio determinou maior redução na concentração de clorofila foliar do que na taxa fotossintética, indicando que plantas de mamão “Golden” cultivadas sob deficiência de nitrogênio mantiveram-se eficientes em termos de redução de $\mathrm{CO}_{2}$ por unidade de clorofila (Figura 3C). Esse resultado evidencia que, mesmo sob deficiência de nitrogênio, o direcionamento desse nutriente para a formação dos componentes dos tilacóides, quando expressos por unidades de clorofila, permanece inalterado e é consistente com as observações de EVANS (1989).

Comparando-se os tratamentos 1,0 e $8,0 \mathrm{molm}^{-3}$ de $\mathrm{N}^{-\mathrm{NO}_{3}}$, observou-se que as reduções provocadas foram, respectivamente, de $84 \%$ na área foliar, de $26,7 \%$ na concentração de nitrogênio e de apenas $18,2 \%$ na taxa fotossintética. Isso significa que plantas de mamão cultivadas sob deficiência de nitrogênio priorizam a redução da área de interceptação da energia solar incidente, ao mesmo tempo em que minimizam a redução da concentração de nitrogênio foliar. Com essa estratégia, essas plantas conseguem minimizar o efeito negativo sobre a capacidade fotossintética por unidade de área foliar, como visto pela pequena redução da taxa fotossintética (18,2\%). Estratégia semelhante é utilizada por plantas de batata (VOS \& Van Der PUTTEN, 1998). Em outras espécies, a exemplo do milho, a prioridade é minimizar reduções na área foliar e na interceptação de luz, em detrimento da concentração de nitrogênio foliar, ocasionando maior redução da atividade fotossintética por unidade de área (VOS et al., 2005).

\section{CONCLUSÕES}

Todos os parâmetros de crescimento das plântulas do mamoeiro foram prejudicados pela deficiência de nitrogênio, sendo a área foliar o componente mais afetado. Sob condição de deficiência de $\mathrm{N}$, foi observado ajuste no particionamento de carbono entre a raiz e a parte aérea. A redução da taxa fotossintética das plantas cultivadas sob deficiência de nitrogênio não foi devida a limitações estomáticas, mas, muito provavelmente, à redução da condutância do mesofilo.

Ciência Rural, v.37, n.1, jan-fev, 2007. 

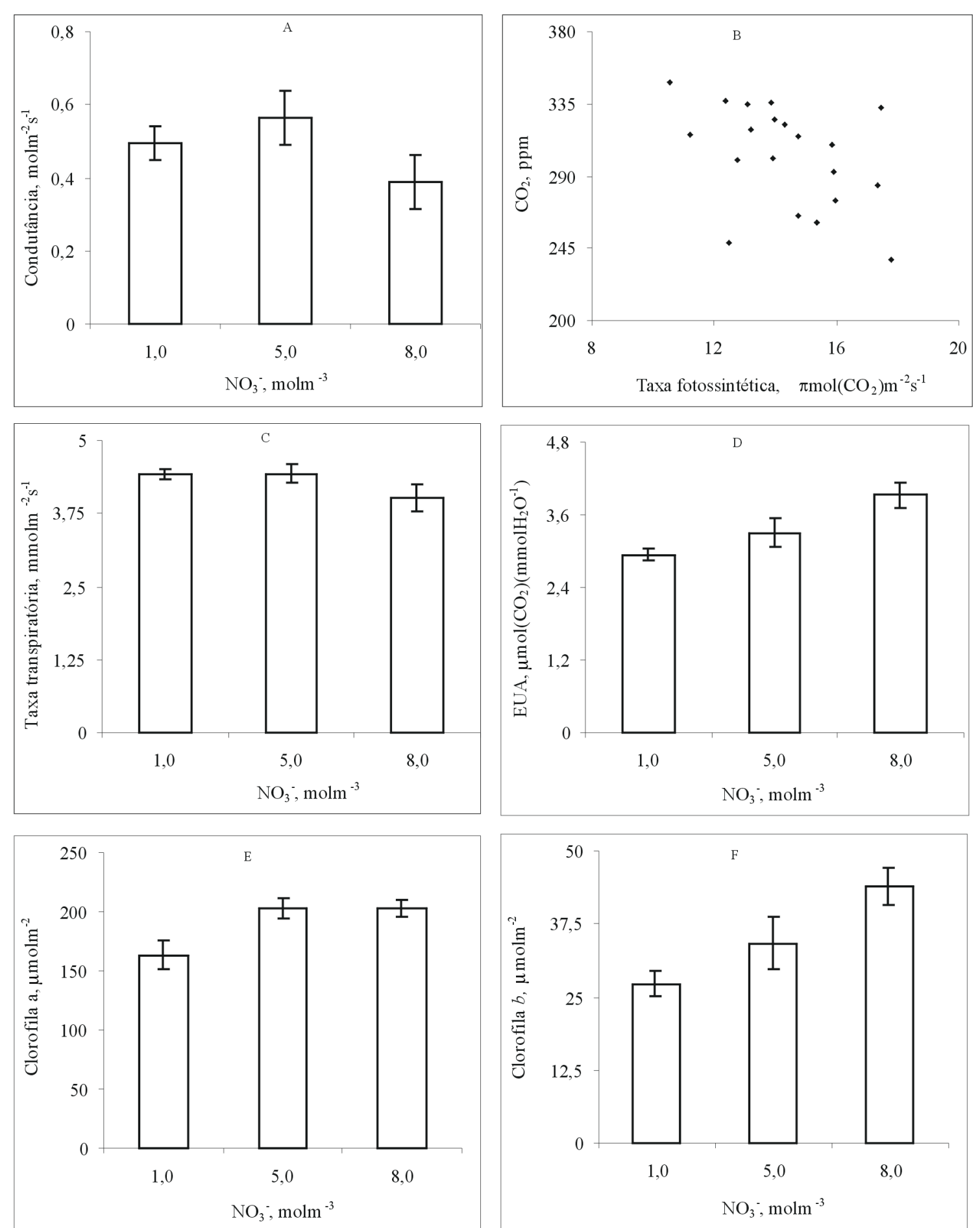

Figura 2 - Efeito de níveis de nitrogênio sobre a condutância estomática (A), correlação entre a concentração interna de $\mathrm{CO}_{2}$ e a taxa fotossintética (B), taxa transpiratória (C), uso eficiente de água (D), clorofilas $a$ (E) e $b$ (F) do mamoeiro “Golden”, cultivado por 61 dias em solução nutritiva. Barras representam o erro padrão da média (n=7). 

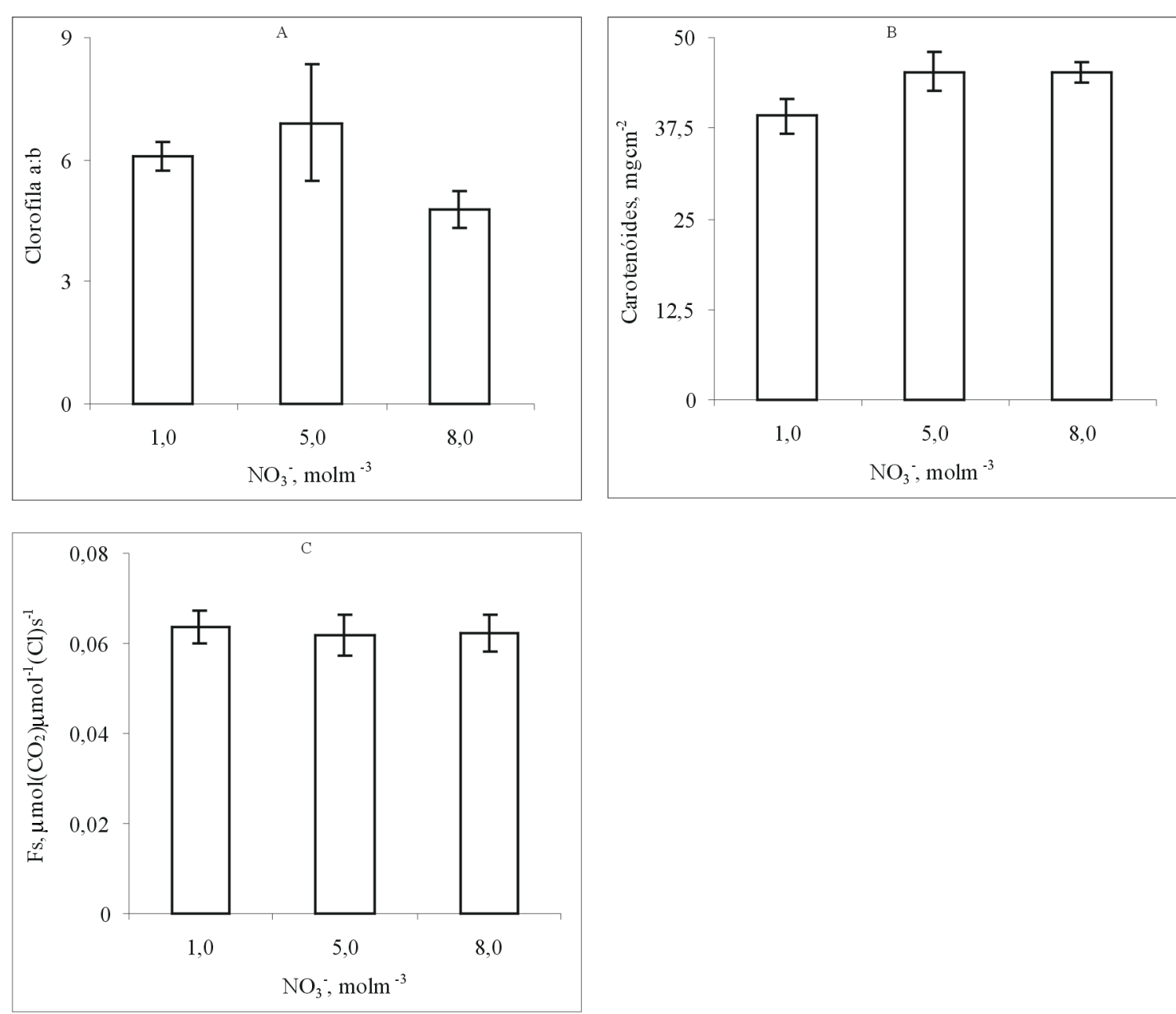

Figura 3 - Efeito de níveis de nitrogênio sobre a relação entre as concentrações das clorofilas $a$ e $b$ (A), carotenóides (B) e a taxa fotossintética expressa em base de clorofila (C) do mamoeiro "Golden”, cultivado por 61 dias em solução nutritiva. Barras representam o erro padrão da média $(\mathrm{n}=7)$.

\section{REFERÊNCIAS}

BONDADA, B.R.; SYVERTSEN, J.P. Concurrent changes in net $\mathrm{CO}_{2}$ Assimilation and chloroplast ultrastructure in nitrogen deficient citrus leaves. Environmental and Experimental Botany, Oxford, v.54, n.1, p.41-48, 2005.

CIOMPI, S. et al. The effect of nitrogen deficiency on leaf gas exchange and chlorophyll fluorescence parameters in sunflower. Plant Science, Limerik, v.118, n.2, p.177-184, 1996.

CORREIA, C.M. et al. Ultraviolet-B radiation and nitrogen affect the photosynthesis of maize: a Mediterranean field study. European Journal of Agronomy, Amsterdan, v.22, n.3, p.337-347, 2005.

CRUZ, J.L. et al. Crescimento e partição de matéria seca e de carbono no mamoeiro em resposta à nutrição nitrogenada. Bragantia, Campinas, v.63, n.3, p.351-361, 2004.
CRUZ, J.L. Efeitos de níveis de nitrato sobre o metabolismo do nitrogênio, assimilação do $\mathrm{CO}_{2}$ e fluorescência da clorofila a em mandioca. 2001. $87 \mathrm{f}$. Tese (Doutorado em Fisiologia Vegetal) - Universidade Federal de Viçosa, Viçosa.

DELÚ-FILHO, N. Efeito do $\mathrm{NO}_{3}{ }^{-}$sobre o crescimento e a atividade das enzimas de assimilação do nitrogênio em plantas jovens de seringueira (Hevea brasiliensis Muell. Arg.). 1994. 87f. Dissertação (Mestrado em Fisiologia Vegetal) - Universidade Federal de Lavras, Lavras.

EGHBALL, B.; MARANVILLE, J.W. Root development and nitrogen influx of corn genotypes grown under combined drought and nitrogen stresses. Agronomy Journal, Madison, v. 85, n.1, p.147-152, 1993.

EVANS, J.R. Photosynthesis and nitrogen relationship in leaves of C3 plants. Oecologia, Berlim, v.78, n.1, p.9-19, 1989. 
GUIDI, L. et al. Growth and photosynthesis of Lycopersicum esculentum (L.) plants as affected by nitrogen deficiency. Biologia Plantarum, Prague, v.40, n.2, p.235-244, 1998.

HELDT, H.W. Plant biochemistry and molecular biology. New York: Oxford University, 1997. 522p.

INSTITUTO BRASILEIRO DE GEOGRAFIA E ESTATISTICA. Capturado em 05 de agosto de 2005. Online. Disponível na Internet: http://www.sidra.ibge.gov.br/ bda/agric/default.asp?t $=5 \& \mathrm{z}=\mathrm{t} \& \mathrm{o}=10 \& \mathrm{u} 1=1 \& \mathrm{u} 2=1 \& \mathrm{u} 3=1 \& \mathrm{u} 4$ $=1 \& u 5=1 \& u 6=1$.

JOVANOVIC, Z. et al. Effects of $\mathrm{N}$ deficiency on leaf growth and cell wall peroxidade activity in contrasting maize genotypes. Plant and Soil, Dordrecht, v.265, n.1-2, p.211-223, 2004.

KOZLOWSKI, T.T; PALLARDY, G.S. Physiology of woody plants. California: Academic, 1997. 411p.

OLIVEIRA, A.M.G.; CALDA R.C. Produção do mamoeiro em função de adubação com nitrogênio, fósforo e potássio. Revista Brasileira de Fruticultura, Jaboticabal, v.26, n.1, p.160163, 2004.

PALMER, S.J. et al. Control of leaf expansion in sunflower (Helianthus annus L.) by nitrogen nutrition. Journal of Experimental Botany, Oxford, v.47, n.3, p.359-368, 1996.

RADIN, J.W.; BOYER, J.S. Control of leaf expansion by nitrogen nutrition in sunflower plants. Role of hydraulic conductivity and turgor. Plant Physiology, Rockville, v.69, n.3, p.771-775, 1982.
RUFTY Jr., T.W. et al. Alterations in internal partitioning of carbon in soybean plants in response to nitrogen stress. Canadian Journal of Botany, Ottawa, v.62, n.4, p.501508, 1984

SUGIHARTO, B. et al. Regulation of expression of carbonassimilating enzymes by nitrogen in maize leaf. Plant Physiology, Rockville, v.92, n.4, p.963-969, 1990

TAIZ, L.; ZEIGER, E. Plant physiology. Massachusetts: Sinauer Associates, 1998. 792p.

TERASHIMA, I.J.; EVANS, J.R. Effects of light and nitrogen on the organization of the photosynthetic apparatus in spinach. Plant Cell Physiology, Tokio, v.29, n.2, p.143-155, 1988.

TERASHIMA, I.J.; HIKOSAKA, J. Comparative ecophysiology of leaf and canopy photosynthesis. Plant Cell Environment, Oxford, v.18, n.9, p.1111-1128, 1995

VOS, J. et al. Effect of nitrogen supply on leaf appearance, leaf growth, leaf nittrogen economy and photosynthetic capacity in maize (Zea mays L.). Field Crop Research, Amsterdam, v.93, n.1, p.64-73, 2005.

VOS, J.; Van Der PUTTEN, P.E.L. Effect of nitrogen supply on leaf growth, leaf nitrogen economy and photosynthetic capacity in potato. Field Crops Research, Amsterdam, v.59, n.1, p.63-72, 1998.

WELLBURN, A.R. The spectral determination of chlorophyll $a$ and $b$, as well as total carotenoids, using various solvents with spectrophotometers of different resolution. Journal of Plant Physiology, Jena, v.144, n.3, p.307-313, 1994. 